\title{
Effect of Various Irrigant Activation Methods and Its Penetration in the Apical Third of Root Canal-In Vitro Study
}

\author{
Delphine Pricilla Antony S. ${ }^{10}$ Pradeep Solete ${ }^{10}$ Ganesh Jeevanandan ${ }^{20}$ Ather Ahmed Syed ${ }^{30}$ \\ Samaher Almahdi ${ }^{3}$ Mohanad Alzhrani ${ }^{4}$ Prabhadevi C. Maganur ${ }^{3}$ (i) Satish Vishwanathaiah ${ }^{30}$
}

${ }^{1}$ Department of Conservative Dentistry and Endodontics, Saveetha Dental College and Hospitals, Saveetha Institute of Medical and Technical Sciences, Saveetha University, Chennai, Tamil Nadu, India 2 Department of Pediatric and Preventive Dentistry, Saveetha Dental College, Saveetha Institute of Medical and Technical Science, Chennai, Tamil Nadu, India

3 Division of Pedodontics, Department of Preventive Dental Sciences, College of Dentistry, Jazan University, Jazan, Kingdom of Saudi Arabia

${ }^{4}$ Ministry of Health, Kingdom of Saudi Arabia

\begin{abstract}
Address for correspondence Satish Vishwanathaiah, BDS, MDS, FICD, FPFA, Division of Pedodontics, Department of Preventive Dental Sciences, College of Dentistry, Jazan University, Jazan, Kingdom of Saudi Arabia (e-mail: drvsatish77@gmail.com).
\end{abstract}

Ganesh Jeevanandan, BDS, MDS, PhD, Department of Pediatric and Preventive Dentistry, Saveetha Dental College, Saveetha Institute of Medical and Technical Science, Chennai, Tamil Nadu, India

Eur J Dent 2023;17:57-61.

\begin{abstract}
Keywords

- endodontic irrigant

- EndoActivator

- iohexol dye

- profit s3

- side-vented needle

Objective The objective of this study was to evaluate the irrigant penetration using iohexol dye with four irrigation techniques.

Methodology Single-rooted premolars were recently extracted and preserved in physiological saline solution. All the samples were standardized to $16 \mathrm{~mm}$. Standard endodontic access was prepared using endoaccess bur (Dentsply Maillefer, Switzerland). The initial patency was established using \#10 k file (Mani, Utsunomiya, Tochigi, Japan) to the working length. The cleaning and shaping were performed using the file system ProFit S3 in the following sequence: P0 (orifice enlarger), PF1 (yellow), PF2 (red) \#25, and PF3 (blue) \#30. The samples were randomly allocated in concealed opaque envelopes into four groups. This was performed by a trained dentist. Fifteen samples were allocated to one group. The groups were divided as follows: Group A-conventional needle (CN), Group B-side-vented needle (SVN), Group C-manual dynamic agitation (MDA), and Group D-EndoActivator (EA). The radiopaque dye irrigant agitation/activation was performed by one operator to prevent operator bias. Following irrigation using the different techniques, digital radiographs were taken, and the measurement was taken from the apical foramen to the point where the dye had penetrated apically for each tooth and the data were entered into an Excel sheet for all the four groups.

Results Comparing the four groups, there was a statistically significant difference among the four groups $(p<0.05)$, thus, favoring the alternate hypothesis. EA had resulted in better penetration of the irrigant compared with the other three groups $(p<0.05)$.

Conclusion It was evident that irrigant penetration was best achieved with the use of an EA followed by MDA, SVNs, and then the $\mathrm{CN}$ when the preparation was done till size 30 (PF3 \#30) using ProFit S3 rotary file system.
\end{abstract}

article published online

February 21, 2022
DOI https://doi.org/

10.1055/s-0041-1742122.

ISSN 1305-7456.
(C) 2022. The Author(s).

This is an open access article published by Thieme under the terms of the Creative Commons Attribution License, permitting unrestricted use, distribution, and reproduction so long as the original work is properly cited. (https://creativecommons.org/licenses/by/4.0/)

Thieme Medical and Scientific Publishers Pvt. Ltd., A-12, 2nd Floor,

Sector 2, Noida-201301 UP, India 


\section{Introduction}

Disinfection is an integral part of root canal treatment along with cleaning and shaping. The root morphology of teeth varies, and to obtain adequate disinfection root canal, irrigant plays a vital role. Irrigation protocol is followed, which provides for chemical dissolution of the pulp tissue, removal of smear layer, dentin debris/shavings, and mechanical uncoupling of biofilm thereby reducing the number of microorganisms. ${ }^{1}$ The activity of the best irrigant is obtained only when it reaches the site of the bacteria within the canal and fulfills its required goal of disinfection. Adequate and effective delivery of the irrigant and activation/agitation of technique play a pivotal role to guarantee adequate quantity is delivered within the root canal and adequately replenished to maintain the desired concentration of the irrigant. The irrigation technique used should bring about a flow property that pushes out the microorganisms, biofilm, and tissue remnants out of the canal ${ }^{2}$ in the coronal direction. The activity of the irrigant should be confined to the root canal only. Irrigants used should provide adequate disinfection, and it should not alter the physical and chemical properties of dentin. ${ }^{3,4}$

The apical third of the root morphology is complex ${ }^{5}$ with numerous lateral canals, apical delta, and apical ramifications. ${ }^{6}$ Disinfection of these areas cannot be adequately obtained only with cleaning and shaping. Irrigants play a major role in the disinfection of these areas and provide the success of the root canal treatment. To obtain adequate and effective disinfection of the root canal, the use of irrigation techniques plays a major role. Different methods or techniques are used such as ultrasonic activation, manual agitation techniques, machine-assisted agitation, continuous irrigation, sonic activation, apical negative-pressure irrigation, laser activation, photo-activated disinfection, and ozone. ${ }^{7}$

The age-old practice was normal syringe irrigation for the delivery of irrigants. This is the most common and popular method due to its simplicity and ease of use. Various syringe and needle sizes were used based on the clinician's requirement. Syringes of size 5 to $20 \mathrm{~mL}$ are commonly used. A wide variety of irrigant delivery needles are used during root canal procedure. ${ }^{2,8,9}$ Needles are usually made of stainless steel, but $\mathrm{NiTi}^{10}$ and recently, plastic is also used which increases the flexibility and ease of use in curved canals. ${ }^{2}$ The diameter of the needle is represented in "gauge" units, ${ }^{10,11}$ the higher the unit value, the finer the needle. Larger size needles were used previously, and a lesser quantity of irrigant was delivered with the restricted flow to the apical region. In recent times, the delivery of irrigant to the total length of the canal is emphasized. The use of smaller needles has obtained recognition. The disadvantage with a smaller needle is that more force is required to deliver the same flow rate, and a minor decrease in the diameter of the needle will lead to an increase in the force required. ${ }^{12}$

Irrigation needles fall under two categories: open-ended and closed-ended. Open-ended needles devise an intense jet of irrigant which is directed apically. ${ }^{10,13}$ The factors that influence the penetration of the irrigant are apical size, taper, and the flow rate of the irrigant. ${ }^{13-16}$ Closed-ended needles create a low-intensity jet ${ }^{14}$ that channels the irrigant toward the root canal walls.

Manual dynamic agitation (MDA) is not a piece of equipment that is used, rather a file (instrument), gutta-percha cone/point, or endodontic brushes are agitated within the root canal along with the irrigant. ${ }^{17}$ This method causes displacement of the endodontic irrigant solution into the canal coronally, apically, and into the isthmus and uninstrumented fins. ${ }^{18}$ After the root canal instrumentation is complete, a gutta-percha point/cone that matches or closely matches the apical preparation is selected ${ }^{19}$ and its tug back or tight fit is verified for the effectiveness of this agitation process. During this agitation process, there can be an extrusion of irrigant through the apical foramen ${ }^{20}$ and to counter this effect, the gutta-percha cone/point is trimmed $1 \mathrm{~mm}$ at the tip to prevent extrusion. ${ }^{17}$

Sonic agitation relies on the transverse oscillation of a tip that is placed within the confines of the root canal to agitate the irrigant at lower frequencies 160 to $190 \mathrm{~Hz}$ for the EndoActivator (EA) (Dentsply Sirona, Charlotte, North Carolina, United States $)^{21}$ to higher frequencies as high as $6,000 \mathrm{~Hz}$ for EDDY (VDW, Munich, Germany). ${ }^{22}$ The agitation process is performed after the delivery of the irrigant using a syringe and needle.

The aim of the current study was to evaluate the depth of penetration of four irrigation techniques using a radiopaque contrast dye. The null hypothesis was that there was no significant difference among the four irrigation techniques used.

\section{Materials and Methods}

Single-rooted premolars were recently extracted and preserved in physiological saline solution. The teeth were examined using a radiograph to identify any canal deviations and calcification of canals. Such teeth were eliminated from the study sample. Sixty teeth samples were randomly divided into four groups and used for evaluating the irrigation technique. The root curvature was standardized according to Schneider's technique to 20 to 40 degrees. The crowns were decoronated to a length of $16 \mathrm{~mm}$ to maintain uniformity of the teeth and were mounted on a wax block. The apical foramen of the roots was sealed using wax to simulate closed system.

Standard endodontic access was prepared using endoaccess bur (Dentsply Maillefer, Switzerland). The initial patency was established using \#10 k file (Mani, Utsunomiya, Tochigi, Japan) to the Working Length (WL). The cleaning and shaping were performed using the file system ProFit S3 in the following sequence: P0 (orifice enlarger), PF1 (yellow), PF2 (red) \#25, and PF3 (blue) \#30. ${ }^{23,24}$ The samples were randomly allocated in concealed opaque envelopes into four groups. This was performed by a trained dentist. Fifteen samples were allocated to one group. The groups were divided as follows: Group Aconventional needle (CN), Group B-side-vented needle (SVN), Group C-MDA, and Group D-EA.

\section{Preparation of dye}

The radiopaque iohexol dye was mixed with $5.25 \%$ sodium hypochlorite by a trained pharmacologist in the proportion 
of $45: 55$ to obtain a radiopaque irrigating solution with a density $(1.0848 \mathrm{~g} / \mathrm{mL})$ and surface tension $(75.60$ dyne $/ \mathrm{cm}$ ) similar to $\mathrm{NaOCl} 2$ to $5 \%{ }^{25}$

The radiopaque dye irrigant agitation/activation was performed by one operator to prevent operator bias. Following irrigation using the different techniques, digital radiographs were taken, and the measurement was taken from the apical foramen to the point where the dye had penetrated apically for each tooth, and the data were entered into an Excel sheet for all the four groups.

\section{Statistical Analysis}

The data obtained were entered into an Excel sheet and the data were transferred to SPSS software. The statistical analysis was performed using the SPSS software version 23.0. Descriptive statistics was performed to calculate the mean and standard deviation. One-way analysis of variance and post hoc Tukey's test were done to compare significance among the four groups.

\section{Results}

Comparing the four groups, there was a statistically significant difference among the four groups $(p<0.05)(-$ Fig. 1 ). The mean and standard deviation of the groups are as follows ,Group A (CN)- 1.23130 .25145 , Group B (SVN)0.9547 0.16444, Group C (MDA)-0.70930.04399, and Group D (EA) - 0.50130 .18185 , respectively, on group-wise comparison, EA was found to be significant compared with other three groups ( $p<0.05$ ), MDA, SVN, and CN, thus favoring the alternate hypothesis. The EA group had a mean and standard deviation of $0.5013 \pm 0.18185$ with a $p<0.05$. Thus, the replacement of irrigant was best achieved with the use of EA.

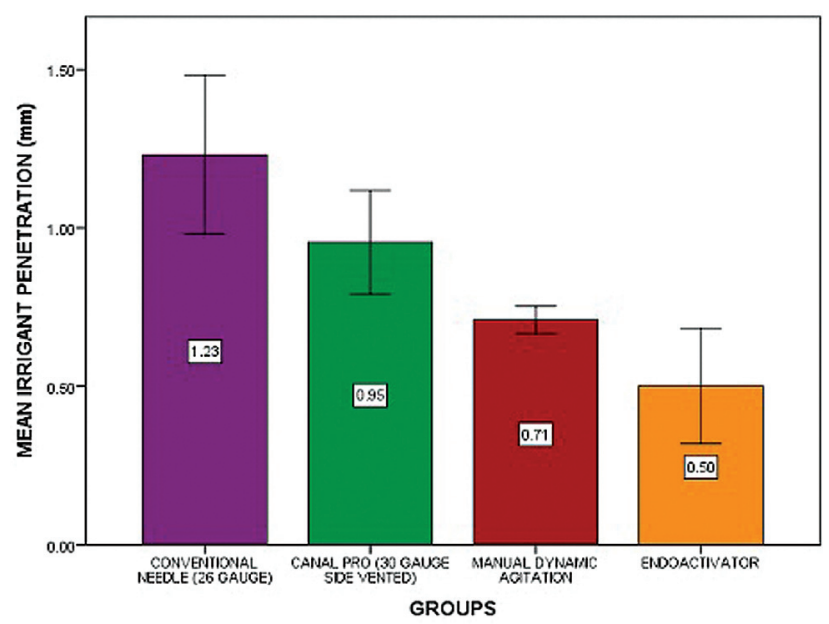

Fig. 1 The bar chart depicts the digital measurement from the apical foramen to the point where the dye has penetrated in the canal of conventional needle (purple), side-vented needle (green), manual dynamic agitation (red), and EndoActivator (yellow). $X$-axis represents the measurement of the distance between the dye and the apical foramen. $Y$-axis represents the four groups of irrigation techniques. There was a statistically significant difference among the four groups at $p<0.05$.

\section{Discussion}

Disinfection in endodontics is achieved by the combined effect of root canal irrigant and endodontic files. Irrigants have two actions, mainly antibacterial action and decalcifying action. ${ }^{26}$ Endodontic irrigant as such does not completely disinfect or reduce the microbial load. Both hand and rotary instruments are constantly improved, ${ }^{27}$ yet more than $40 \%$ of the root canal surface remain uninstrumented. ${ }^{28}$ It requires a better delivery system and agitation to bring about the best of the irrigant used in achieving disinfection of the root canal. The aim of a delivery system is to transfer or transport the required quantity of the irrigant into the main canal, and agitation or activation carries this irrigant further into the canal system and enhances the disinfection process. ${ }^{2}$ The effectiveness of endodontic irrigation was the depth of penetration of the needle and the distribution of the irrigant beyond the tip of the needle which was much less than expected according to Chow. ${ }^{28,29}$

In the current study, the patency was established to size \#10 using a K-file, and then cleaning and shaping were achieved using the rotary file system ProFit S3. The canals were prepared till the size PF3 \#30 with copious irrigation. The teeth were then randomly divided into four groups. Group A$\mathrm{CN}$ (26-gauge needle), Group B-CanalPro-30-gauge needle, Group C-MDA, and Group D-EA. During instrumentation, the radiopaque irrigating solution was delivered passively according to the respective group technique, and irrigant penetration depth was measured using digital radiographs in the conventional group. The measurement was done using a digitalanalog scale from coronal to apical direction.

In the current study, there was a significant difference among the four groups in the dye penetration to the apical region. The $\mathrm{CN}$ of 26 gauge has a metric size of $0.45 \mathrm{~mm}$ and an external diameter of 0.440 to $0.470 \mathrm{~mm}$. These openended needles generate an intense jet of irrigant which penetrates apically. ${ }^{10,13}$ The depth of penetration of irrigant depends on the apical size and taper of the root canal to which it has been prepared and the flow rate of irrigant. ${ }^{10,13,15,16}$ An increase in the taper size leads to better penetration of the irrigant and subsequent flushing out of debris and removal of the smear layer. Khademi et al stated that apical instrumentation to a \#30 size file with 0.06 coronal taper is effective for the removal of debris and smear layer from the apical portion of root canals. ${ }^{28,30}$ In this study, it was found that an increase in root canal taper that is, \#30 resulted in deeper penetration of the needle and enhanced the irrigant replacement. It was found the penetration of dye was less with a 26-gauge needle compared with SVN.

The external diameter of the 30 -gauge needle is $0.3 \mathrm{~mm}$ which corresponds to 30 size instruments. In this study, the flat open-ended needles were placed $2 \mathrm{~mm}$ short of WL and SVNs $1 \mathrm{~mm}$ short or where the needle first binds to the canal. In an in vitro study done by Boutsioukis et $\mathrm{al},{ }^{10}$ it was reported that the SVN achieved irrigant replacement to the WL only at the $1-\mathrm{mm}$ position, whereas the open-ended flat needle was able to achieve complete replacement even when positioned at $2 \mathrm{~mm}$ short of the WL. A study by Srirekha et al stated that 


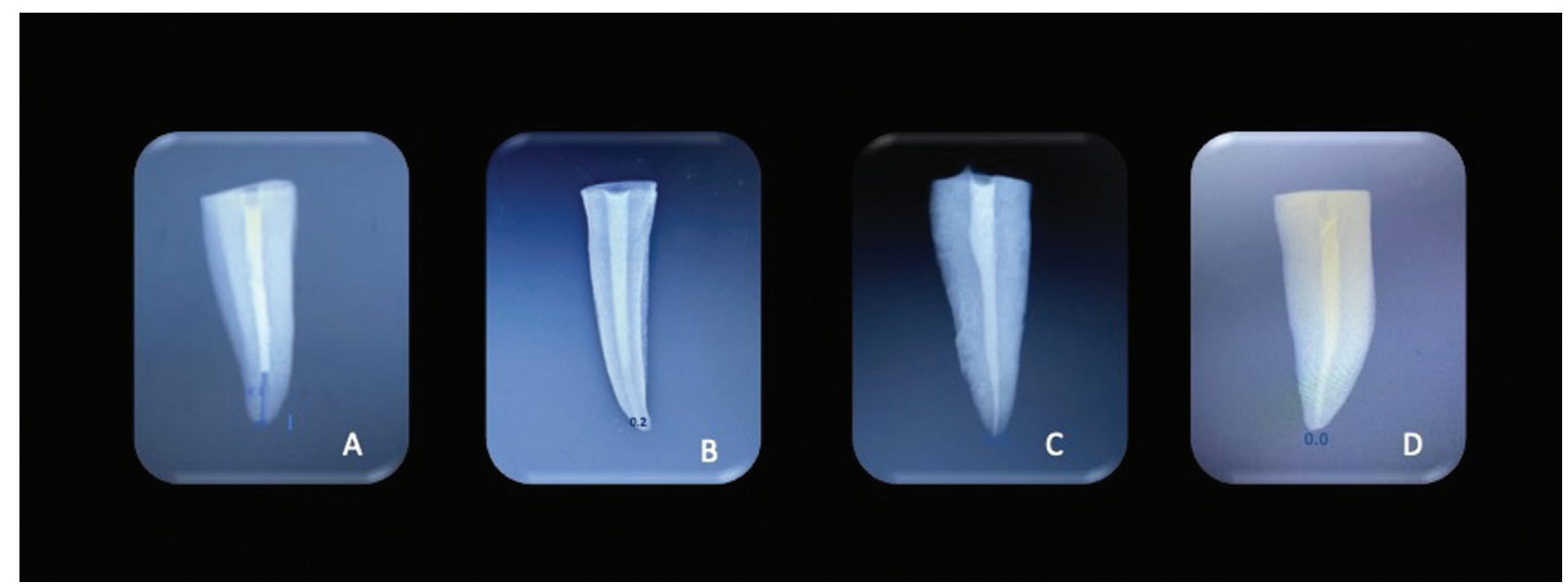

Fig. 2 Digital radiographs of the teeth with dye penetration. (A) Conventional needle 26 gauge, (B) side-vented needle, (C) manual dynamic agitation, and (D) EndoActivator.

increased preparation of the canal and the use of flat-ended needles and SVNs had no significant difference in irrigant penetration ${ }^{28}$ which is contradicting the current study.

MDA helps the distribution of the irrigant and its exchange within the root canal and enhances the effectiveness of the irrigant solution used. In this process, the irrigant present in the canal reaches the root apex and disrupts the vapor lock. ${ }^{31}$ It creates an increased intracanal pressure change within the canal during the forward and backward movement of the gutta-percha cone within the canal which creates turbulences that enhance the diffusion of shear stresses. ${ }^{32} \mathrm{~A}$ previous study showed the risk of apical extrusion during MDA, ${ }^{33}$ and this can be strongly avoided by the agitation of the gutta-percha cone $1 \mathrm{~mm}$ short of the WL. ${ }^{32} \mathrm{In}$ the current study, MDA achieved better penetration of the irrigant compared with 26 -gauge $\mathrm{CN}$ and 30 -gauge SVN.

Subsonic activation is the third most preferred technique following syringe irrigation and ultrasonic activation. ${ }^{34,35}$ For group EA, the irrigant delivery protocol was followed as stated by Ramamoorthi et al. ${ }^{36}$ In the current study, EA which comes under subsonic activation had better penetration of the dye (-Fig. 2), which implies that more irrigant solutions had been in contact with the canal walls. Kanter et al reported that EA aided in better removal of debris in lateral canals. ${ }^{37}$ It was stated by Bago et al that EA had a superior effect compared with needle irrigation. ${ }^{38}$ Sato et al stated that effectiveness of the irrigant is influenced by the quantity, temperature, and its interaction with the agents. ${ }^{39}$ Iandolo et al in 2020 stated that irrigant activation enhances the efficacy of irrigants. ${ }^{40}$ Iandolo et al in 2019 stated that endodontic irrigant activation aids in flushing out of debris and it helps eliminating bacterial load from the root canal. ${ }^{41}$

In this study, it was evident that the EA performed better than the other three groups, and in the order, EA, MDA, SVN, followed by the $\mathrm{CN}$.

\section{Conclusion}

Within the limitations of the study, it was evident that irrigant penetration was best achieved with the use of an
EA followed by MDA, SVNs, and then CN. The current study being an in vitro study needs more clinical trials to substantiate the obtained results in the future.

Conflict of Interest

None declared.

\section{References}

1 Zehnder M. Root canal irrigants. J Endod 2006;32(05):389-398

2 Boutsioukis C, Arias-Moliz MT. Irrigating Solutions, Devices, and Techniques. Endodontic Materials in Clinical Practice 2021: 133-180

3 Kulkarni S, Mustafa M, Ghatole K, et al. Evaluation of $2 \%$ chlorhexidine and $2 \%$ sodium fluoride as endodontic irrigating solutions on root dentine microhardness: an in vitro study. Eur J Dent 2021; 15(02):253-258

4 Dubey S, Saha SG, Rajkumar B, Dhole TK. Comparative antimicrobial efficacy of selected root canal irrigants on commonly isolated microorganisms in endodontic infection. Eur J Dent 2017;11(01): $12-16$

5 Vertucci FJ. Root canal anatomy of the human permanent teeth. Oral Surg Oral Med Oral Pathol 1984;58(05):589-599

6 Peters OA. Current challenges and concepts in the preparation of root canal systems: a review. J Endod 2004;30(08):559-567

7 Plotino G, Cortese T, Grande NM, et al. New technologies to improve root canal disinfection. Braz Dent J 2016;27(01):3-8

8 Moser JB, Heuer MA. Forces and efficacy in endodontic irrigation systems. Oral Surg Oral Med Oral Pathol 1982;53(04):425-428

9 Kahn FH, Rosenberg PA, Gliksberg J. An in vitro evaluation of the irrigating characteristics of ultrasonic and subsonic handpieces and irrigating needles and probes. J Endod 1995;21(05): 277-280

10 Boutsioukis C, Lambrianidis T, Vasiliadis L. Clinical relevance of standardization of endodontic irrigation needle dimensions according to the ISO 9,626:1991 and 9,626:1991/Amd 1:2001 specification. Int Endod J 2007;40(09):700-706

11 Stainless Steel Needle Tubing for the Manufacture of Medical Devices-Requirements and Test Methods. London: BSI British Standards; 2015

12 Boutsioukis C. Syringe irrigation revisited. ENDO EPT 2019;13 (02):101-113

13 Chen JE, Nurbakhsh B, Layton G, Bussmann M, Kishen A. Irrigation dynamics associated with positive pressure, apical negative pressure and passive ultrasonic irrigations: a computational fluid dynamics analysis. Aust Endod J 2014;40(02):54-60 
14 Boutsioukis C, Verhaagen B, Versluis M, Kastrinakis E, Wesselink $\mathrm{PR}$, van der Sluis LWM. Evaluation of irrigant flow in the root canal using different needle types by an unsteady computational fluid dynamics model. J Endod 2010;36(05):875-879

15 Boutsioukis C, Lambrianidis T, Verhaagen B, et al. The effect of needle-insertion depth on the irrigant flow in the root canal: evaluation using an unsteady computational fluid dynamics model. J Endod 2010;36(10):1664-1668

16 Verhaagen B, Boutsioukis C, Heijnen GL, van der Sluis LWM, Versluis M. Role of the confinement of a root canal on jet impingement during endodontic irrigation. Experiments in fluids 2012;53(06):1841-1853

17 Machtou P. Manual dynamic activation (MDA) technique. In Endodontic Irrigation. Springer, Cham; 2015:149-155

18 van der Sluis LWM, Boutsioukis C, Jiang LM, Macedo R, Verhaagen B, Versluis M. The Root Canal Biofilm. InChávez de Paz E, Sedgley CM, Kishen A, editors, Root Canal Irrigation. Berlin Heidelberg: Springer; 2015. (Springer Series on Biofilms; 9). Doi: 10.1007/ 978-3-662-47415-0_9

19 Jiang LM, Lak B, Eijsvogels LM, Wesselink P, van der Sluis LWM. Comparison of the cleaning efficacy of different final irrigation techniques. J Endod 2012;38(06):838-841

20 Boutsioukis C, Psimma Z, Kastrinakis E. The effect of flow rate and agitation technique on irrigant extrusion ex vivo. Int Endod J 2014;47(05):487-496

21 Jiang LM, Verhaagen B, Versluis M, van der Sluis LWM. Evaluation of a sonic device designed to activate irrigant in the root canal. J Endod 2010;36(01):143-146

22 Neuhaus KW, Liebi M, Stauffacher S, Eick S, Lussi A. Antibacterial efficacy of a new sonic irrigation device for root canal disinfection. J Endod 2016;42(12):1799-1803

23 Antony DP. ProFitS3-Brochure. Accessed on: May 27, 2021 at: https://s3profit.com

24 Antony SDP, Subramanian AK, Nivedhitha MS, Solete P. Comparative evaluation of canal transportation, centering ability, and dentin removal between ProTaper Gold, One Curve, and Profit S3: an in vitro study. J Conserv Dent 2020;23(06):632-636

25 Vera J, Hernández EM, Romero M, Arias A, van der Sluis LWM. Effect of maintaining apical patency on irrigant penetration into the apical two millimeters of large root canals: an in vivo study. J Endod 2012;38(10):1340-1343

26 Dioguardi M, Gioia GD, Illuzzi G, Laneve E, Cocco A, Troiano G. Endodontic irrigants: different methods to improve efficacy and related problems. Eur J Dent 2018;12(03):459-466

27 Peters OA, Boessler C, Paqué F Root canal preparation with a novel nickel-titanium instrument evaluated with micro-computed tomography: canal surface preparation over time. J Endod 2010;36 (06):1068-1072
28 Srirekha A, Shrivastava P, Vijay R, Savitha A, Archana S. Effect of Apical Preparation Size and Taper on Irrigant Penetration in Apical Third of Root Canal using Two Different Endodontic Needles: An In Vivo Study. Jf Dent and Oral Biol 2017;2(13):1083

29 Chow TW. Mechanical effectiveness of root canal irrigation. J Endod 1983;9(11):475-479

30 Khademi A, Yazdizadeh M, Feizianfard M. Determination of the minimum instrumentation size for penetration of irrigants to the apical third of root canal systems. J Endod 2006;32(05): 417-420

31 Voegeli G, Bella ED, Mekki M, Machtou P, Bouillaguet S. Effect of a modified irrigation protocol on the cleanliness of moderately curved canals. Eur J Dent 2021;15(01):90-95

32 Machtou PP. Manual dynamic activation technique. Clinical Dentistry Reviewed 2018;2:21

33 Boutsioukis C, Psimma Z, van der Sluis LWM. Factors affecting irrigant extrusion during root canal irrigation: a systematic review. Int Endod J 2013;46(07):599-618

34 Dutner J, Mines P, Anderson A. Irrigation trends among American Association of Endodontists members: a web-based survey. J Endod 2012;38(01):37-40

35 de Gregorio C, Arias A, Navarrete N, Cisneros R, Cohenca N. Differences in disinfection protocols for root canal treatments between general dentists and endodontists: a web-based survey.J Am Dent Assoc 2015;146(07):536-543

36 Ramamoorthi S, Nivedhitha MS, Divyanand MJ. Comparative evaluation of postoperative pain after using endodontic needle and EndoActivator during root canal irrigation: a randomised controlled trial. Aust Endod J 2015;41(02):78-87

37 Kanter V, Weldon E, Nair U, et al. A quantitative and qualitative analysis of ultrasonic versus sonic endodontic systems on canal cleanliness and obturation. Oral Surg Oral Med Oral Pathol Oral Radiol Endod 2011;112(06):809-813

38 Bago I, Plečko V, Gabrić Pandurić D, Schauperl Z, Baraba A, Anić I Antimicrobial efficacy of a high-power diode laser, photo-activated disinfection, conventional and sonic activated irrigation during root canal treatment. Int Endod J 2013;46(04):339-347

39 Sato T, Fujimaki R, Suzuki J, Hamada N, Tani-Ishii N, Handa K. Bactericidal effect of a novel alkaline EDTA root canal cleaning solution. Eur J Dent 2021;15(03):546-550

40 Iandolo A, Abdellatif D, Amato M, et al. Dentinal tubule penetration and root canal cleanliness following ultrasonic activation of intracanal-heated sodium hypochlorite. Aust Endod J 2020;46 (02):204-209

41 Iandolo A, Dagna A, Poggio C, Capar I, Amato A, Abdellatif D. Evaluation of the actual chlorine concentration and the required time for pulp dissolution using different sodium hypochlorite irrigating solutions. J Conserv Dent 2019;22(02):108-113 